\title{
Serum paraoxonase-1 activity in Egyptian premenopausal women with metabolic syndrome and its relation with recurrent pre-eclampsia risk
}

\author{
Moushira Zaki ${ }^{1 *}$, Walaa A Basha', Walaa Yousef', Ahmed S Ismail', Eman Youness ${ }^{2}$, Tamer Hussein², Osama Azmy ${ }^{3}$ \\ ${ }^{1}$ Biological Anthropology Department, Medical Research Division, National Research Centre, Giza, Egypt. \\ ${ }^{2}$ Medical Biochemistry Department, Medical Research Division, National Research Centre, Giza, Egypt. \\ ${ }^{3}$ Reproductive Health Research Department, Medical Research Division, National Research Centre, Giza, Egypt.
}

\begin{tabular}{|c|c|}
\hline ARTICLE INFO & ABSTRACT \\
\hline Article history: & \multirow{5}{*}{$\begin{array}{l}\text { Background: Association of paraoxonase-1 (PON-1) with the metabolic syndrome (MS) and recurrent pre-eclampsia } \\
\text { has not been previously investigated among Egyptian premenopausal women. Pre-eclampsia is a multisystem disorder } \\
\text { and its etiopathogenesis has not yet been fully understood. Aim: The aim of the study is to investigate serum } \\
\text { PON-1 activity in Egyptian women with MS and assess its potential link with the incidence of recurrent pre-eclampsia. } \\
\text { Method: The study group consisted of } 60 \text { premenopausal women with MS and } 60 \text { healthy controls. In the MS group, } \\
26 \text { patients had past history of recurrent pre-eclampsia. The enzymatic activity of serum PON-1 was measured by } \\
\text { spectrophotometer. Serum lipids were measured by enzymatic colorimetric methods using a Hitachi auto-analyzer. } \\
\text { Results: MS cases with and without recurrent pre-eclampsia showed significantly reduced PON-1 activity compared } \\
\text { to healthy controls. Significant negative correlations were observed between PON-1 levels and BMI, SBP, DBP, serum } \\
\text { total cholesterol, TG and LDL-C and positive correlation with HDL-C in MS cases either with or without recurrent } \\
\text { pre-eclampsia. In addition, MS cases with history of recurrent pre-eclampsia showed significantly lower levels of } \\
\text { PON-1 than those without. Conclusions: Serum PON-1 is significantly reduced in women with MS and might alter } \\
\text { their lipid profile. Low PON-1 levels could contribute to the great risk of recurrent pre-eclampsia in MS women. }\end{array}$} \\
\hline Received on: 08/10/2017 & \\
\hline Accepted on: 10/12/2017 & \\
\hline Available online: $27 / 02 / 2018$ & \\
\hline $\begin{array}{l}\text { Key words: } \\
\text { Serum PON-1, metabol- } \\
\text { ic syndrome, recurrent } \\
\text { pre-eclampsia, serum lipids, } \\
\text { women. }\end{array}$ & \\
\hline
\end{tabular}

\section{INTRODUCTION}

Paraoxonase-1 (PON-1) is a high-density lipoprotein (HDL) associated esterase enzyme that has a well-established antioxidant and anti-inflammatory properties (Kunutsor et al., 2016). It protects both low-density lipoprotein cholesterol (LDL-C) and HDL cholesterol (HDL-C) against oxidative damage (Manolescu et al., 2015). The antioxidant and anti-inflammatory properties of PON-1 have been found to be associated with CVD risk; although this association is partially dependent on HDL-C levels (Eren et al., 2013). There is a variation among individuals and populations in the PON-1 activity (Browne et al., 2007).

\footnotetext{
${ }^{*}$ Corresponding Author

Biological Anthropology Department, Medical Research Division, National Research Centre, Giza, Egypt.E-mail: moushiraz@yahoo.com
}

A reduced PON-1 activity has been reported in clinical conditions accompanied by low HDL-C such as the metabolic syndrome (MS) and Type 2 diabetes mellitus (DM) (Mackness et al., 1991). Nevertheless, there is a lacking in the current knowledge concerning the mechanisms responsible for regulating PON-1 activity.

Metabolic syndrome (MS) is a prevalent and complicated disorder that characterized by insulin resistance, hyperglycemia, abdominal obesity, arterial hypertension, atherogenic dyslipidemia, a prothrombotic state, and a proinflammatory state. These risk factors lead to the development of type $2 \mathrm{DM}$ and cardiovascular (CV) diseases. Lots of studies observed low levels of PON-1 activity in patients with DM (Flekač et al., 2008). Several studies have examined the PON-1 activity in metabolic syndrome and insulin resistance patients, however, results from non-diabetic subjects showed contradictions. In non-diabetic Swiss population, an association has been observed between the significantly lower 
serum PON-1 concentrations and metabolic syndrome (Garin et al., 2005). However, A study on non-diabetic Turkish individuals showed no differences in the PON-1 activity between metabolic and non-metabolic cases (Tabur et al., 2010). In non-diabetic Japanese subjects, Yamada et al. (2001) have observed a positive correlation between the Homeostasis Model Assessment (HOMA) index and HDL-corrected PON-1 activity. In patients with MS, the role of PON-1 against peroxidation of LDL-C may be substantial. Decreased activity of PON-1 might play a role in the pathogenesis of atherosclerosis via rising the susceptibility to lipid peroxidation in patients with MS.

Pre-eclampsia is a disorder characterized by hypertension and proteinuria and causes maternal and perinatal mortality (Roberts and Cooper, 2001), though its etiopathogenesis has not yet been fully understood. In pre-eclampsia, a disturbance in the physiological remodeling of the uterine spiral arteries into dilated uteroplacental vessels observed in normal pregnancies is evident (Craven et al., 1998). A disagreement between studies that investigated the serum PON-1 activities in pre-eclamptic subjects has been observed. Some studies reported significantly higher paraoxonase activity in pre-eclamptic pregnant women compared to controls (Yaghmaei et al., 2011). Higher paraoxonase activity in severe compared to mild pre-eclampsia has also been observed. Other studies, however, found lower PON-1 in preeclamptic pregnant women compared to the controls (Genc et al., 2011). On the other hand, other authors have reported no differences in the paraoxonase activity between normal, mild and severe pre-eclamptic pregnant women (Sarandöl et al., 2004). As PON-1enzyme plays an antioxidant role in protecting LDL from oxidation, it has been assumed that PON-1 enzyme might be associated with diseases that oxidative stress implicated in their pathogenesis. However, the association between serum PON-1 activity and MS with recurrent pre-eclampsia has not yet been elucidated.

So, the aim of this study was to measure serum PON-1 activity in women with MS and to investigate its relation with recurrent pre-eclampsia risk.

\section{MATERIALS AND METHODS}

\section{Subjects}

Sixty premenopausal women with MS and 60 healthy $(31.5 \pm 2.9$ yrs.) women were included in the study. In the MS group, 26 patients had past history of recurrent pre-eclampsia. old with MS.

Inclusion criteria for subjects were women $<40$ years

Exclusion criteria for subjects were women with endocrine, metabolic kidney disease, or medical problems other than MS.

Subjects without and with MS, defined according to the revised NCEP-ATP III criteria (Grundy et al., 2005). Further inclusion criteria were cases with past history of pre-eclampsia in previous pregnancy/pregnancies. The subjects were patients in the obesity clinic at the National Research Centre. Control subjects included in the study were age match healthy women with normotensive and uncomplicated pregnancies history. Pre- eclampsia was defined as an increase in blood pressure to at least $140 / 90 \mathrm{mmHg}$ after the 20 week of gestation, an increase in diastolic blood pressure (DBP) of at least $15 \mathrm{mmHg}$ from the level measured before the 20 week, an increase in systolic blood pressure (SBP) of at least $30 \mathrm{mmHg}$ from the level measured before the 20 week, combined with proteinuria (at least $0.3 \mathrm{~g}$ per 24 hours) (Program, 2000).

The diagnosis of pre-eclampsia was established in accordance with the definition of the American College of Obstetricians and Gynecologist (Canadian Task Force on the Periodic Health Examination, 1994; Diaz et al., 2006).

Plasma lipids levels in control and MS subjects are shown in Table 1. Controls and patients were not taking lipid-lowering drugs, angiotensin-converting enzyme inhibitors, antioxidants, or other medication that could affect lipid metabolism. Smokers were excluded from the study, because cigarette smoke has been shown to inhibit paraoxonase activity. Furthermore, subjects with a current or recent illness were excluded from the study.

Informed consent was obtained from each participating subject. This research has been approved by the Ethical Committee of National Research Centre, Egypt (number = 16361), in accordance with the World Medical Association's Declaration of Helsinki.

\section{Methods}

\section{Ascertainment of incident hypertension}

Incident hypertension was defined as systolic blood pressure (SBP) of $\geq 140 \mathrm{mmHg}$, a diastolic BP of $\geq 90 \mathrm{mmHg}$, or the use of antihypertensive medication, in accordance with recommendations from the Seventh Joint National Committee on Prevention, Detection, Evaluation, and Treatment of High Blood Pressure (Expert Panel on Detection, 2001). We used this definition to ensure consistency of hypertension in previous medical reports. Data on the use of antihypertensive medications were ascertained by questionnaires at each examination.

\section{Anthropometric measurements}

Anthropometric variables included body weight and height. Height was measured with the patients standing with their backs leaning against the stadiometer of the same scale. BMI was calculated as weight in kilograms divided by height in meters squared $\left(\mathrm{kg} / \mathrm{m}^{2}\right)$. Anthropometric measurements were obtained according to standardized equipment and following the recommendations of the International Biological Program (Tanner et al., 1969). Obese subjects had BMI greater than or equal to 30 $\mathrm{kg} / \mathrm{m}^{2}$ and overweight subjects had BMI ranged $25-29.9 \mathrm{~kg} / \mathrm{m}^{2}$.

\section{Laboratory tests}

Venous blood samples were collected by direct venipuncture after an overnight fast (minimum $12 \mathrm{~h}$ ).

\section{Measurement of paraoxonase activity}

The enzymatic activity of serum PON-1 was measured by spectrophotometer (Sigma Chemical Co., St. Louis, MO). Paraoxonase activity was expressed as U/1 serum (Haagen and Brock, 1992). The inter-assay CV was $8 \%$. 


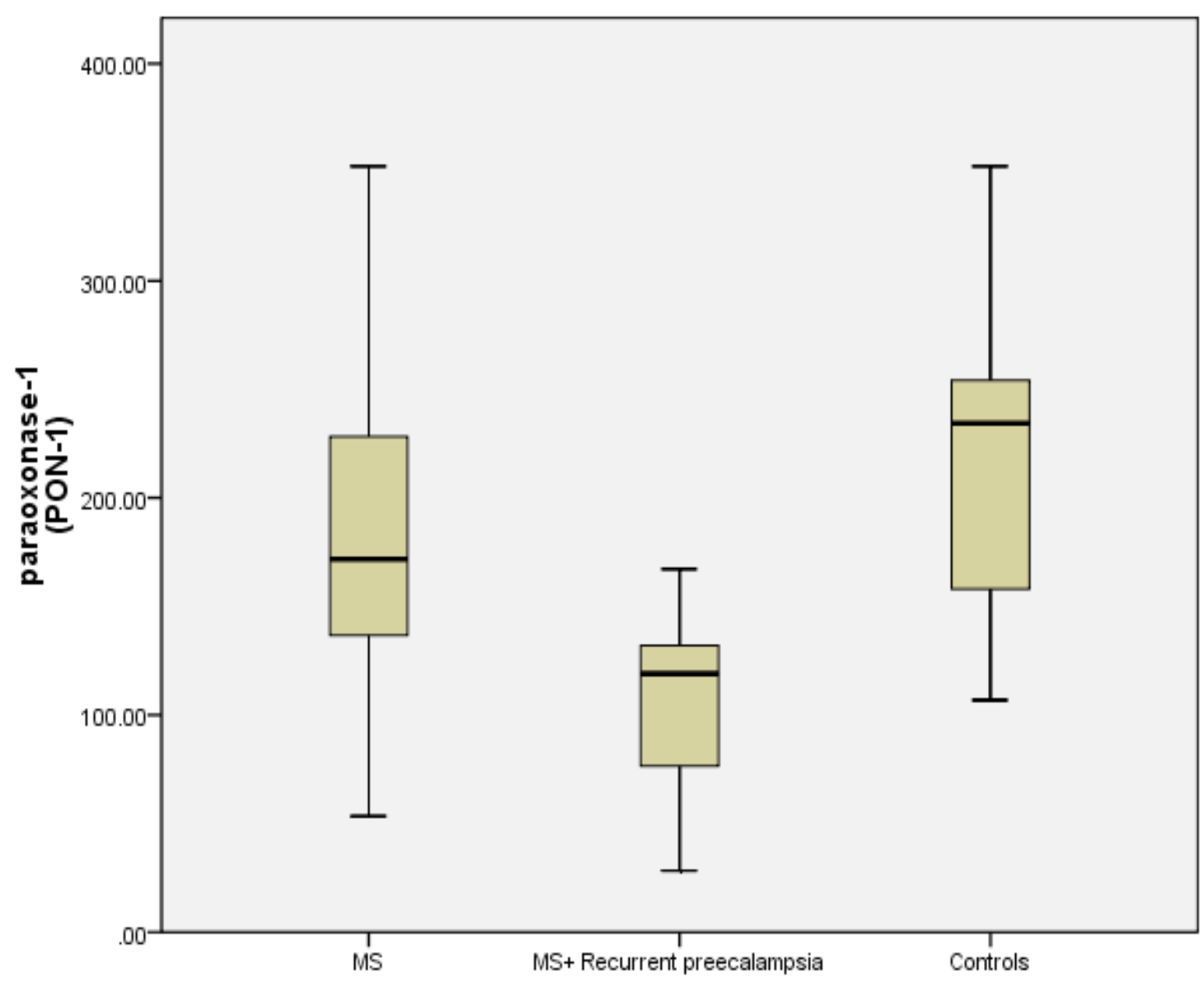

Fig. 1: Serum paraoxonase 1 activity in the MS group, MS + recurrent pree-clampsia subgroup and controls.

\section{Blood lipids and HOMA-IR measurements}

Fasting plasma glucose and serum lipids (total cholesterol, high-density lipoprotein cholesterol (HDL-C) triglycerides (TG)) were measured by enzymatic colorimetric methods using a Hitachi auto-analyzer 704 (Roche Diagnostics. Switzerland) (Hirschler et al., 2010). Low density lipoprotein cholesterol (LDL-C) was calculated according to certain equation (LDL-C $=$ Total cholesterol - Triglycerides $/ 5+$ HDL-C). Serum insulin concentration was analyzed by chemiluminescent immunoassay (Immulite 2000, Siemens, Germany). Insulin resistance was determined by the Homeostasis Model Insulin Resistance (HOMA-IR) which is calculated as the product of the fasting plasma insulin level (IU/mL) and the fasting plasma glucose level (mmol/L), divided by 22.5 (Matthews et al., 1985). Each subject had a clinical history taken and physical examination was also performed.

\section{Statistical analysis}

Data were statistically analyzed using Statistical Package for the Social Sciences version 16 software (SPSS Inc.; Chicago, IL, USA). Parameters were expressed as mean \pm SD. The correlations of variables were assessed in each group using Pearson Correlation Analysis. ANOVA tests were performed comparing 3 groups, and 2 groups were compared using independent T-tests.
To determine significant differences between groups, the PostHoc test with Bonferroni correction was used. Pearson correlation test was used to study the relation between serum paraoxonase, lipid and metabolic parameters. For comparing clinical and laboratory results between the groups, we used Student t-tests or Mann-Whitney $U$ test. The level of statistical significance was set at $\mathrm{p}<0.05$.

\section{RESULTS}

Table 1 shows clinical and metabolic data of MS cases with and without recurrent pre-eclampsia and control group. Mean ages of the three groups were similar. In MS group FBG, BMI, TC, TG, SBP, DBP, and HOMA-IR levels were significantly higher than controls while PON-1 and HDL-C were significantly lower. Similar results were observed in MS with recurrent pre-eclampsia subgroup as compared to the control group. Moreover, MS cases with recurrent pre-eclampsia showed significant higher BMI and HOMA-IR and lower PON-1 compared to those without.

Analyses of the correlation between lipid and metabolic parameters with enzymatic activities of PON-1 are shown in Table 2. Correlation analyses showed significant negative correlation between PON-1 and BMI, total cholesterol, LDL-C, triglycerides and HOMA-IR and significant positive correlation with HDL-C in MS cases. In addition, a similar pattern of correlations between the enzyme activity and metabolic and biochemical parameters was 
observed in women that had recurrent pre-eclampsia and MS.

Table 1: Clinical characteristics, activity of paraoxonase (PON-1), metabolic and lipid parameters in serum of women with MS, recurrent pre-eclampsia and controls.

\begin{tabular}{|c|c|c|}
\hline Variables & Group & Mean \pm SD \\
\hline \multirow{3}{*}{ Age (years) } & MS $(n=34)$ & $31.2 \pm 3.61$ \\
\hline & $\begin{array}{l}\text { MS + Recurrent pre-eclampsia } \\
\qquad(\mathrm{n}=26)\end{array}$ & $33.4 \pm 3.22$ \\
\hline & Controls $(\mathrm{n}=60)$ & $32.5 \pm 4.2$ \\
\hline \multirow{3}{*}{ PON-1 } & MS $(n=34)$ & $180.98 \pm 22.54^{\mathrm{a}}$ \\
\hline & $\begin{array}{c}\text { MS + Recurrent pre-eclampsia } \\
(\mathrm{n}=26)\end{array}$ & $106.33 \pm 27.41^{\mathrm{ab}}$ \\
\hline & Controls $(\mathrm{n}=60)$ & $222.47 \pm 25.02$ \\
\hline \multirow{3}{*}{ BMI $\left(\mathrm{kg} / \mathrm{m}^{2}\right)$} & MS $(n=34)$ & $28.61 \pm 6.84^{\mathrm{a}}$ \\
\hline & $\begin{array}{c}\text { MS + Recurrent pre-eclampsia } \\
(\mathrm{n}=26)\end{array}$ & $34.22 \pm 3.23^{\mathrm{ab}}$ \\
\hline & Controls $(\mathrm{n}=60)$ & $23.23 \pm 4.91$ \\
\hline \multirow{3}{*}{$\mathrm{FPG}(\mathrm{mg} / \mathrm{dL})$} & MS $(n=34)$ & $93.34 \pm 23.70^{\mathrm{a}}$ \\
\hline & $\begin{array}{c}\text { MS + Recurrent pre-eclampsia } \\
(\mathrm{n}=26)\end{array}$ & $121.71 \pm 23.83^{a}$ \\
\hline & Controls $(\mathrm{n}=60)$ & $85.71 \pm 16.72$ \\
\hline \multirow{3}{*}{$\mathrm{TC}(\mathrm{mg} / \mathrm{dL})$} & MS $(n=34)$ & $188.82 \pm 46.96$ \\
\hline & $\begin{array}{c}\text { MS + Recurrent pre-eclampsia } \\
(\mathrm{n}=26)\end{array}$ & $210.75 \pm 34.14$ \\
\hline & Controls $(\mathrm{n}=60)$ & $186.20 \pm 30.773$ \\
\hline \multirow{3}{*}{$\mathrm{TG}(\mathrm{mg} / \mathrm{dL})$} & MS $(n=34)$ & $162.44 \pm 31.66^{\mathrm{a}}$ \\
\hline & $\begin{array}{l}\text { MS + Recurrent pre-eclampsia } \\
\qquad(\mathrm{n}=26)\end{array}$ & $165.50 \pm 32.75^{\mathrm{a}}$ \\
\hline & Controls $(\mathrm{n}=60)$ & $86.67 \pm 30.951$ \\
\hline \multirow{3}{*}{$\begin{array}{l}\text { HDL-C (mg/ } \\
\text { dL) }\end{array}$} & MS $(n=34)$ & $42.30 \pm 11.68^{\mathrm{a}}$ \\
\hline & $\begin{array}{l}\text { MS + Recurrent pre-eclampsia } \\
\qquad(\mathrm{n}=26)\end{array}$ & $43.00 \pm 7.07^{\mathrm{a}}$ \\
\hline & Controls $(\mathrm{n}=60)$ & $55.33 \pm 8.92$ \\
\hline \multirow{3}{*}{$\begin{array}{l}\text { LDL-C (mg/ } \\
\text { dL) }\end{array}$} & MS $(n=34)$ & $123.75 \pm 30.556^{\mathrm{a}}$ \\
\hline & $\begin{array}{l}\text { MS + Recurrent pre-eclampsia } \\
\qquad(\mathrm{n}=26)\end{array}$ & $124.25 \pm 29.88^{\mathrm{a}}$ \\
\hline & Controls $(\mathrm{n}=60)$ & $127.47 \pm 26.99$ \\
\hline \multirow{3}{*}{$\mathrm{SBP}(\mathrm{mmHg})$} & MS $(n=34)$ & $127.05 \pm 7.15^{\mathrm{a}}$ \\
\hline & $\begin{array}{l}\text { MS + Recurrent pre-eclampsia } \\
\quad(\mathrm{n}=26)\end{array}$ & $128.50 \pm 9.82^{\mathrm{a}}$ \\
\hline & Controls $(\mathrm{n}=60)$ & $96.67 \pm 6.14$ \\
\hline \multirow{3}{*}{ DBP $(\mathrm{mmHg})$} & MS $(n=34)$ & $92.05 \pm 8.490^{\mathrm{a}}$ \\
\hline & $\begin{array}{c}\text { MS + Recurrent pre-eclampsia } \\
\qquad(\mathrm{n}=26)\end{array}$ & $96.50 \pm 7.07^{\mathrm{a}}$ \\
\hline & Controls $(\mathrm{n}=60)$ & $70.42 \pm 8.107$ \\
\hline \multirow{3}{*}{ HOMA-IR } & MS $(n=34)$ & $2.68 \pm .47^{\mathrm{a}}$ \\
\hline & $\begin{array}{l}\text { MS + Recurrent pre-eclampsia } \\
\qquad(\mathrm{n}=26)\end{array}$ & $3.55 \pm .02^{\mathrm{ab}}$ \\
\hline & Controls $(\mathrm{n}=60)$ & $1.46 \pm .51$ \\
\hline
\end{tabular}

${ }^{\mathrm{a} P} P<0.001 v s$. control subject. ${ }^{\mathrm{b}} P<0.001 v s . M S$.

Figure 1 illustrates the level of PON-1 in the three groups. Box plot shows mean (SD) of MS, MS + recurrent pre-eclampsia subgroup and control group. Women with MS + recurrent preeclampsia had the lowest mean $(106.33 \pm 27.41)$ level of PON-1 compared to both control $(222.47 \pm 25.02)$ and MS cases without pre-eclampsia (180.98 \pm 22.54$)$. The lower boundary of the box is the 25 th percentile and the upper boundary is the 75 th percentile. The bold line inside the box represents the median. The largest and smallest observed values that are not extreme values are also shown.

Table 2: Correlation of enzymatic activity of PON-1 with metabolic and lipid parameters in women with MS and MS + Recurrent pre-eclampsia.

\begin{tabular}{|c|c|c|c|c|}
\hline & \multicolumn{4}{|c|}{ PON-1 } \\
\hline & \multicolumn{2}{|c|}{$\operatorname{MS}(n=34)$} & \multicolumn{2}{|c|}{$\begin{array}{c}\text { MS + Recurrent pre-eclampsia } \\
(\mathbf{n}=\mathbf{2 6})\end{array}$} \\
\hline & $\mathbf{r}$ & $\mathbf{p}$ & $\mathbf{r}$ & $\mathbf{p}$ \\
\hline HOMA-IR & -.34 & .01 & -.35 & .01 \\
\hline FBG (mg/dl) & -.38 & .01 & -.58 & .001 \\
\hline $\mathrm{TC}(\mathrm{mg} / \mathrm{dl})$ & -.39 & .02 & -.46 & .001 \\
\hline TG (mg/dl) & -.32 & .05 & -.52 & .005 \\
\hline HDL-C $(\mathrm{mg} / \mathrm{dl})$ & .32 & .05 & .35 & .05 \\
\hline LDL-C $(\mathrm{mg} / \mathrm{dl})$ & -.30 & .05 & -.36 & .01 \\
\hline $\mathrm{SBP}(\mathrm{mmHg})$ & -.36 & .01 & -.37 & .01 \\
\hline DBP $(\mathrm{mmHg})$ & -.31 & .05 & -.34 & .01 \\
\hline BMI $\left(\mathrm{kg} / \mathrm{m}^{2}\right)$ & -.29 & .05 & -.37 & .01 \\
\hline
\end{tabular}

HOMA-IR: homeostasis model assessment-insulin resistance; FBG: fasting glucose; TC: total cholesterol; TG: triglycerides; HDL-C: high density lipoprotein cholesterol; LDL-C: low density lipoprotein cholesterol; SBP: systolic blood pressure; DBP: diastolic blood pressure; r: Pearson productmoment correlation coefficient or Spearman's rank correlation coefficient as appropriate.

\section{DISCUSSION}

It is well known that obesity is associated with insulin resistance. It has been found that hyperinsulinaemia as a marker of insulin resistance increase the risk of mild pre-eclampsia. The complex connection between obesity, insulin resistance and preeclampsia is not yet completely understood. Weight loss in obese individuals has health benefits that could justify getting rid of extra weight before pregnancy (Bhattacharya et al., 2009). In our study, subjects with MS showed, as expected, significantly higher BMI, HOMA-IR, in addition to dyslipidemia and hypertension. MS cases with recurrent pre-eclampsia cases showed significantly higher BMI and HOMA-IR compared to MS and control groups.

In agreement with our results, a previous study found higher risk of recurrent pre-eclampsia (19.3\%) among obese women compared to those with normal BMI (11.2\%) (Mostello et al., 2008). Results of the present study showed significantly lower PON-1 and HDL-C in both MS and MS with recurrent preeclampsia subjects in comparison to the control group. Moreover, PON-1 activity was found to be significantly lower in MS cases with recurrent pre-eclampsia than those without pre-eclampsia. In aggrement with our results, Genc and colleagues (2011) reported low PON- activity in pre-eclampsia cases.

Some studies have reported a correlation between serum paraoxonase activity and several lipid and lipoprotein parameters such as triglycerides and HDL (Sözmen et al., 1999). We found similar correlations in the present study. Decreased PON-1 activity has been previously reported in MS cases compared to control, however, Tabur et al. (2010) showed that non-diabetic MS does not affect serum paraoxonase activity. Reduced serum PON-1 
activity is likely to be found in clinical conditions accompanied by low HDL cholesterol such as MS and Type 2 diabetes mellitus (T2DM) (Garin, et al., 2005). Furthermore, Women who suffered from Polycystic Ovarian Syndrome (PCOS) and obesity showed elevated insulin resistance and significantly lower PON-1 levels (Dursun et al., 2005). The protective role of Paraoxonase against LDL and HDL oxidation is probably related to its ability to hydrolyze some oxidized phospholipids (Watson et al., 1995). In the present study, significantly negative correlations have been found between the PON-1 activity and blood pressure in MS cases either with or without pre-eclampsia. According to an extensive prospective study, no association between serum PON-1 and the future risk of hypertension has been found (Kunutsor et al., 2017a). Although the same study has reported an independent and inverse association between HDL-C and incident hypertension. Other studies have also reported the inverse and independent association between the HDL-C and the risk of hypertension (Tohidi et al., 2012).

In the present study, PON-1 activity was positively correlated with HDL-C in both MS cases with or without preeclampsia. HDL has antithrombotic activities as it is able to sweep cholesterol out of the atheromatous arteries. PON-1 is an important constituent of HDL and it has antioxidant and anti-inflammatory properties and has its site of action on HDL (Dullaart et al., 2013). Furthermore, PON-1 has a protective role against atherosclerosis and cardiovascular disease (Sentí et al., 2003). Lots of evidence suggest that the antioxidant properties of HDL and its capacity in protecting LDL oxidation could be attributed to PON-1 activity. HDL-C is involved in the commonly used cardiovascular risk algorithms (Task et al., 2016) and it is a substantial risk factor for atherosclerotic cardiovascular disease (CVD).

The protective association between HDL-C and cardiometabolic outcomes is evident, so, it was not expected to find no association between PON-1 and hypertension. However, it has also been shown that there is no association between PON-1 and type 2 diabetes although, the inverse independent association between HDL-C and type 2 diabetes is evident (Kunutsor et al., 2017b) indicting that the association is independent of and not modified by PON-1. So, apparently, there might be significant pathophysiologic variations between HDL-C and PON-lin the pathogenesis of these cardio-metabolic outcomes. It is possible that these results might reflect the different HDL subclasses or particle sizes, which apparently affect its protective ability against LDL oxidation. It has been suggested that lipids play a role in the development of hypertension, although the mechanisms of this process are not fully understood. In contrast to total cholesterol, LDL-C, triglycerides and apolipoprotein B which are linked to an increased risk of hypertension, HDL-C has a protective role (Halperin et al., 2006). The underlying mechanism of the associations between dyslipidemia and the incidence of hypertension might be through endothelial dysfunction. The precise mechanism affecting low PON-1 levels in MS is still not fully understood. Although a decline in the PON-1 activity has been reported in MS, PON-1 codon 192 genotype distribution was found to be similar in both MS cases and controls (Sentí et al., 2003). It has been demonstrated that lipid-lowering treatments improve PON-1 serum activity (Ribas et al., 2004).
In conclusion, our study showed that PON-1 serum activity was reduced in the MS group as well as in MS with recurrent pre-eclampsia subgroup as compared to controls. Therefore, it is important to measure the serum PON-1 activity in women with MS to improve the power of identifying cases at high risk of pregnancy complications and in interventions against metabolic-related disorders.

\section{ACKNOWLEDGMENTS}

This work was supported by grant from National Research Centre, Egypt.

\section{REFERENCES}

Bhattacharya S, Campbell DM, Smith NC. Pre-eclampsia in the second pregnancy: Does previous outcome matter? Eur J Obstet Gynecol Reprod Biol 2009;144:130-4.

Browne RW, Koury ST, Marion S, Wilding G, Muti P, Trevisan M. Accuracy and biological variation of human serum paraoxonase 1 activity and polymorphism (Q192R) by kinetic enzyme assay. Clin Chem 2007;53:310-7.

Canadian Task Force on the Periodic Health Examination. The Canadian guide to clinical preventive health care. Canadian Government Pub Centre1994.

Craven CM, Morgan T, Ward K. Decidual spiral artery remodelling begins before cellular interaction with cytotrophoblasts. Placenta 1998;19:241-52.

Diaz A, Laufer MR, Breech LL. American College of Obstetricians and Gynecologists Committee on Adolescent Health Care. Menstruation in girls and adolescents: using the menstrual cycle as a vital sign. Pediatrics. 2006;118: 2245-2250.

Dullaart RPF, Kwakernaak AJ, Dallinga-Thie GM. The positive relationship of serum paraoxonase-1 activity with apolipoprotein $\mathrm{E}$ is abrogated in metabolic syndrome. Atherosclerosis 2013;230:6-11.

Dursun P, Demirtaş E, Bayrak A, Yarali H. Decreased serum paraoxonase 1 (PON-1) activity: an additional risk factor for atherosclerotic heart disease in patients with PCOS? Hum Reprod 2005;21:104-8.

Eren E, Yilmaz N, Aydin O. Functionally defective high-density lipoprotein and paraoxonase: a couple for endothelial dysfunction in atherosclerosis. Cholesterol 2013.

Expert Panel on Detection E. Executive summary of the Third Report of the National Cholesterol Education Program (NCEP) expert panel on detection, evaluation, and treatment of high blood cholesterol in adults (Adult Treatment Panel III). Jama 2001;285:2486.

Flekač M, Škrha J, Zídková K, Lacinová Z, Hilgertová J, Flekac M. Paraoxonase 1 Gene Polymorphisms and Enzyme Activities in Diabetes Mellitus. Physiol Res 2008;57:717-26.

Garin M-CB, Kalix B, Morabia A, James RW. Small, dense lipoprotein particles and reduced paraoxonase- 1 in patients with the metabolic syndrome. J Clin Endocrinol Metab 2005;90:2264-9.

Genc H, Uzun H, Benian A, Simsek G, Gelisgen R, Madazli R, et al. Evaluation of oxidative stress markers in first trimester for assessment of pre-eclampsia risk. Arch Gynecol Obstet 2011;284:1367-73.

Grundy SM, Cleeman JI, Daniels SR, Donato KA, Eckel RH, Franklin BA, et al. Diagnosis and management of the metabolic syndrome. Circulation 2005;112:2735-52.

Haagen L, Brock A. A new automated method for phenotyping arylesterase (EC 3.1. 1.2) based upon inhibition of enzymatic hydrolysis of 4-nitrophenyl acetate by phenyl acetate. Clin Chem Lab Med 1992;30:391-6.

Halperin RO, Sesso HD, Ma J, Buring JE, Stampfer MJ, Gaziano JM. Dyslipidemia and the risk of incident hypertension in men. Hypertension 2006;47:45-50.

Hirschler V, Oestreicher K, Maccallini G, Aranda C. Relationship between obesity and metabolic syndrome among Argentinean elementary school children. Clin Biochem 2010;43:435-41. 
Kunutsor SK, Bakker SJL, James RW, Dullaart RPF. Serum paraoxonase-1 activity and risk of incident cardiovascular disease: the PREVEND study and meta-analysis of prospective population studies. Atherosclerosis 2016;245:143-54.

Kunutsor SK, Kieneker LM, Bakker SJL, James RW, Dullaart RPF. The inverse association of HDL-cholesterol with future risk of hypertension is not modified by its antioxidant constituent, paraoxonase-1: The PREVEND prospective cohort study 2017a.

Kunutsor SK, Kieneker LM, Bakker SJL, James RW, Dullaart RPF. Incident type 2 diabetes is associated with HDL, but not with its antioxidant constituent-paraoxonase-1: The prospective cohort PREVEND study. Metabolism 2017b;73:43-51.

Mackness MI, Harty D, Bhatnagar D, Winocour PH, Arrol S, Ishola $\mathrm{M}$, et al. Serum paraoxonase activity in familial hypercholesterolaemia and insulin-dependent diabetes mellitus. Atherosclerosis 1991;86:193-9.

Manolescu BN, Busu C, Badita D, Stanculescu R, Berteanu M. Paraoxonase 1 - an Update of the Antioxidant Properties of High- Density Lipoproteins. Maedica (Buchar) 2015;10:173-7.

Matthews DR, Hosker JP, Rudenski AS, Naylor BA, Treacher DF, Turner RC. Homeostasis model assessment: insulin resistance and $\beta$-cell function from fasting plasma glucose and insulin concentrations in man. Diabetologia 1985;28:412-9.

Mostello D, Kallogjeri D, Tungsiripat R, Leet T. Recurrence of pre-eclampsia: effects of gestational age at delivery of the first pregnancy, body mass index, paternity, and interval between births. Am J Obstet Gynecol 2008;199:55-e1.

Program NHBPE. Report of the national high blood pressure education program working group on high blood pressure in pregnancy. Am J Obstet Gynecol 2000;183:s1-22.

Ribas V, Sánchez-Quesada JL, Antón R, Camacho M, Julve J, Vila L, et al. Human apolipoprotein A-II enrichment displaces paraoxonase from HDL and impairs its antioxidant properties. Circ Res 2004;95:789-97.

Roberts JM, Cooper DW. Pathogenesis and genetics of preeclampsia. Lancet 2001;357:53-6.

Sarandöl Emre, Şafak Özlem, Dirican Melahat UG. Oxidizability of apolipoprotein B-containing lipoproteins and serum paraoxonase/ arylesterase activities in pre-eclampsia. Clin Biochem 2004;37:990-6.

Sentí M, Tomás M, Fitó M, Weinbrenner T, Covas M-I, Sala J, et al. Antioxidant paraoxonase 1 activity in the metabolic syndrome. J Clin Endocrinol Metab 2003;88:5422-6.
Sözmen B, Delen Y, Girgin FK, Sözmen EY. Catalase and paraoxonase in hypertensive type 2 diabetes mellitus: correlation with glycemic control. Clin Biochem 1999;32:423-7.

Tabur S, Torun AN, Sabuncu T, Turan MN, Celik H, Ocak AR, et al. Non-diabetic metabolic syndrome and obesity do not affect serum paraoxonase and arylesterase activities but do affect oxidative stress and inflammation. Eur J Endocrinol 2010;162:535-41.

Tanner JM, Hiernaux J, Jarman S, Weiner JS, Lourie JA. Growth and physique studies. Hum Biol A Guid to F Methods IBP Handb 1969;9:160

Task FM, Piepoli MF, Hoes AW, Agewall S, Albus C, Brotons C, et al. 2016 European Guidelines on cardiovascular disease prevention in clinical practice: The Sixth Joint Task Force of the European Society of Cardiology and Other Societies on Cardiovascular Disease Prevention in Clinical Practice (constituted by representati. Atherosclerosis 2016;252:207.

Tohidi M, Hatami M, Hadaegh F, Azizi F. Triglycerides and triglycerides to high-density lipoprotein cholesterol ratio are strong predictors of incident hypertension in Middle Eastern women. J Hum Hypertens 2012;26:525.

Watson AD, Berliner JA, Hama SY, La Du BN, Faull KF, Fogelman AM, et al. Protective effect of high density lipoprotein associated paraoxonase. Inhibition of the biological activity of minimally oxidized low density lipoprotein. J Clin Invest 1995;96:2882.

Yaghmaei M, Hashemi M, Azarian A, Moazeni-Roodi A, Mokhtari M, Naghavai A, et al. Association of L55M and Q192R polymorphisms of paraoxonase-1 gene with pre-eclampsia. Arch Med Res 2011;42:324-8.

Yamada A, Shoji T, Tahara H, Emoto M, Nishizawa Y. Effect of insulin resistance on serum paraoxonase activity in a nondiabetic population. Metabolism 2001;50:805-11.

How to cite this article:

Zaki M, Basha WA, Yousef W, Ismail AS, Youness E, Hussein T, Azmy O. Serum paraoxonase-1 activity in Egyptian premenopausal women with metabolic syndrome and its relation with recurrent pre-eclampsia risk. J App Pharm Sci, 2018; 8(02): 054-059. 